\title{
The interference of optical zoom in human and machine classification of pollen grain images
}

\author{
Felipe Silveira Brito Borges ${ }^{1}$, Juliana Velasques Balta ${ }^{2}$, Milad Roghanian ${ }^{2}$, Ariadne Barbosa Gonçalves ${ }^{3}$, \\ Marco Alvarez ${ }^{4}$, Hemerson Pistori ${ }^{2,3}$ \\ ${ }^{1}$ University of Debrecen (UNIDEB), Debrecen, Hungary \\ ${ }^{2}$ Universidade Católica Dom Bosco (UCDB), Campo Grande, MS, Brazil \\ ${ }^{3}$ Universidade Federal de Mato Grosso do Sul (UFMS), Campo Grande, MS, Brazil \\ ${ }^{4}$ University of Rhode Island (URI), Kingstown, RI, United States
}

\begin{abstract}
Palynology can be applied to different areas, such as archeology and allergy, where it is constantly growing. However, no publication comparing human classifications with machine learning classifications at different optical scales has been found in the literature. An image dataset with 17 pollen species that occur in Brazil was created, and machine learning algorithms were used for their automatic classification and subsequent comparison with humans. The experiments presented here show how machine and human classification behave according to different optical image scales. Satisfactory results were achieved, with $98.88 \%$ average accuracy for the machine and $45.72 \%$ for human classification. The results impact a single scale pattern for capturing pollen grain images for both future computer vision experiments and for a faster advance in palynology science.
\end{abstract}

Index Terms-Machine Learning, Computer Vision, Microscopy, Palynology, Pollen Grains.

\section{INTRODUCTION}

The identification of pollen grains is related to the field of palynology, which is the study of pollen grains, spores, and some types of diatoms. Palynology can be valuable in many applications, such as quality control of bee products, ie honey [1]; collecting evidence at a crime scene to assist criminal investigations through geographical locations of the suspects [2], [3]; or in the mapping of past climate through the reconstruction of past environments [4], for the identification of fossil pollen. Interestingly, pollen can also help in the oil exploration industry as they serve to map potential fields [5].

There are several pollen analyses procedures, for example through human eye recognition using a microscope, electronic scanning identification, and laser particle detection, being the human eye analysis is the most popular and broad used, as there is no need for large equipment tools. It is done with palynological slides with grain samples, a microscope, and a specialist in the field. On the other hand, many mistakes are commonly made, these may be caused by the fatigue exerted in the accomplishment of this task. Another important point is the indispensability of a specialist in the field, creating a dependency because there are few qualified professionals for this task [6].

Corresponding author: Felipe Silveira Brito Borges (email: felipesilveira@ieee.org).
According to [7], grain recognition is done through common external attributes such as shape, symmetry, size, and texture, which can sometimes be very subtle and lead to classification errors by experts in the field. The construction of a computer system to automate pollen grain classification is of great value, as the steps taken by palynologists are time-consuming and could be reduced from months to a few hours by an automated identification system. Thus, the contribution of this work helps in three points for the advance of this technology, being:

- Creation of a new pollen grain image dataset;

- Analysis of an ideal optical scale for image capture; and

- Comparison of two computational classification techniques against human classification.

First, a new annotated dataset including 903 images of 17 pollen types were constructed and made openly available to support the development of new machine vision systems. Second, the efficiency of machine learning algorithms was measured in the task of classifying this pollen, thus assisting in future studies for automation and deep learning techniques were implemented and explored to build a machine vision system that can classify images of pollen. Finally, this work supports a new approach to measure how human vision classification compares to machine vision. Thus, experiments were conducted to find the best configuration for this system and the results are reported.

The next section presents a brief review of the state-ofthe-art regarding the automation of the pollen classification task and is followed by the materials and methods section. The results, discussion, and conclusions are then reported, and future work is later proposed.

\section{RELATED WORK}

There were found in the literature eight different approaches to pollen grains classifications (Table I). However, none of them took care of the optical zoom as well as its distinction from human classification.

Quinta et al. [8] applied Optimum-Path Forest (OPF) on honey bee pollen grains. The best result using this technique was a performance of $75.27 \%$ by applying the algorithm C4.5 on 200 pollen grains images divided into six different species. 
TABLE I

DIFFERENT APPROACHES ON THE LITERATURE ABOUT POLLEN GRAIN CLASSIFICATION. AS THEY ARE DIFFERENT WORKS, THE RESULTS COLUMN HAS NOT THE SAME EVALUATION METRIC.

\begin{tabular}{cllccc}
\hline Author & \multicolumn{1}{c}{ Approach } & $\begin{array}{c}\text { No. of } \\
\text { images }\end{array}$ & $\begin{array}{c}\text { No. of } \\
\text { classes }\end{array}$ & $\begin{array}{c}\text { Results } \\
(\%)\end{array}$ \\
\hline 1 & {$[8]$} & Optimum-Path Forest & 200 & 6 & 75 \\
2 & {$[9]$} & Watershed & 333 & 4 & 98 \\
3 & {$[10]$} & Shape and texture & 291 & 3 & 89 \\
4 & {$[11]$} & Bag-of-Words & 315 & 9 & 71 \\
5 & {$[12]$} & Neural Networks & 345 & 17 & 92 \\
6 & {$[13]$} & Wavelet Transform & 30 & 7 & 79 \\
7 & {$[7]$} & CST+BOW & 805 & 23 & 64 \\
8 & {$[14]$} & DCNN's & 805 & 23 & 97 \\
\hline
\end{tabular}

After pattern recognition experiments, Andrade et al. [9] had the objective of classifying pollen grain images using texturebased segmentation and Watershed. The following procedures were used: attribute extraction of texture attributes, followed by a Gaussian blurring and finally a use of image thresholding by an interactive selection method. This technique obtained as a final result a correct classification percentage of $98.93 \%$, using a dataset containing 333 images from 4 different species of pollen grains.

To classify Urticaceae species, which can cause respiratory diseases, analysis of shape and texture characteristics were used. These species are very common throughout the year so, according to the researchers, it is very interesting to have a system that can recognize the pollens of this species. They obtained an accuracy of $89 \%$ using the MDC classifier on three pollen types, which was higher than that achieved by a palynologist in routine analysis [10].

Similarly, the use of the Bag-of-Words (BOW) technique allowed Gonçalves et al. [11] to generate a histogram of each used image containing their respective characteristics. Experiments resulted in the generation of a dictionary of 2048 descriptors for each image, followed by classifications with supervised learning algorithms. As a final result, the best result was obtained through the SVM algorithm, which obtained $71 \%$ accuracy in the correct classification percentage.

Using a dataset of 345 images from 17 different pollen species, which involved 17 subgenera of tropical honey plants in Costa Rica and Central America, the authors [12] were able to get a $92.81 \%$ accuracy using 50 imaging features and artificial neural networks. Recently, the same authors used the Bag-of-Visual-Words and reached 95.8\%, however they used only one pollen species, Betula.

From the same point of view, Diogo et al. [13] adopt the Wavelet Transform, in a dataset with 7 different species. The main objective was the reduction of unnecessary attributes. The algorithms used were C4.5 and KNN, obtaining not very good results, especially for the shape attribute where it obtained $57 \%$ of F-rate with the $\mathrm{C} 4.5$ algorithm. However, when more attributes were combined it obtained a significant improvement, with a $79 \%$ rate in the F-measure.

In contrast, according to Barbosa et al. [7], the best technique that should be used to automate pollen grain classification is the combination of attributes with Bag-of-Words.
In this experiment, the CST algorithm was created, its name is based on the use of color, shape, and texture attributes. The authors also presented a new pollen grain images dataset for machine learning experiments, POLEN23e, which is the biggest one already published, and reached a CCR of $64 \%$ with CST+BOW and the C-SVC classifier.

However, Sevillano and Aznarte [14] improved the machine classification rate on POLEN23e using deep learning convolutional neural networks. The authors implemented three models of deep learning and used transfer learning for the classification, achieving $97 \%$ of correct classification, being the dataset split into train-test groups.

\section{MATERIAL AND MethodS}

\section{A. Image Dataset}

An image dataset was created, named Polen40k, containing 38.880 different images. Experiments were conducted with two machine learning paradigms, shallow and deep, with 40 different configurations in each.

In Figure 1, it is possible to visualize a sample of each pollen grain species present in the image dataset.

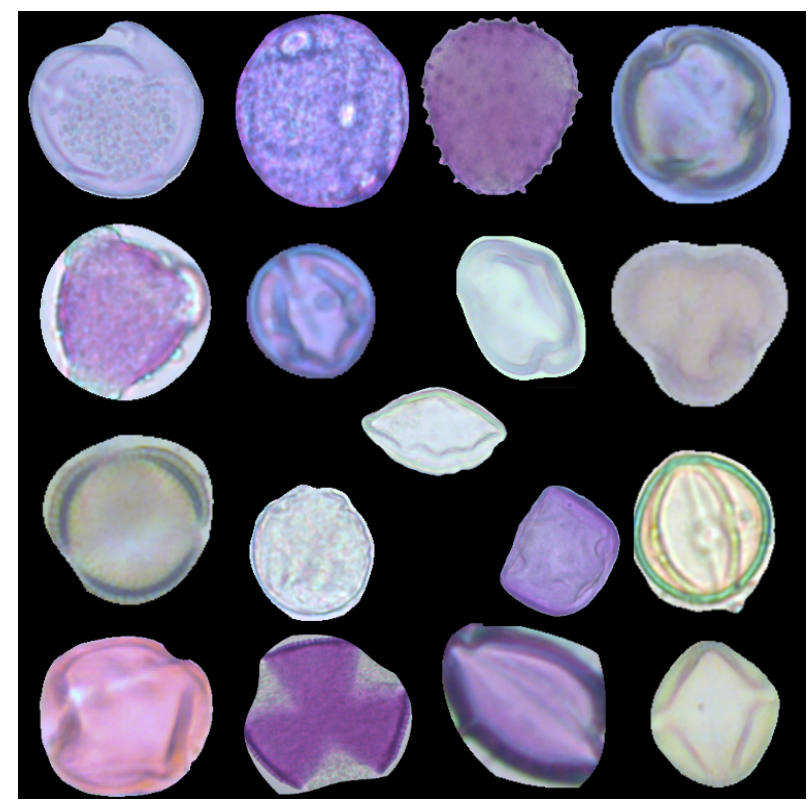

Fig. 1. A sample of each pollen type from our Polen40k dataset. The dataset consists in 38,880 images of 17 pollen species, captured by the author in the laboratory. The 17 species are: Azadirachta indica, Banisteria argyrophylla, Bauhinia, Bixa orellana, Camptostema ellipticum, Casearia aculeata, Cocos nucifera, Euphorbia pulcherrima, Handroanthus heptaphyllus, Hidrocleys nymphoides, Inga vera, Leucaena leucocephala, Matayba guianensis, Mitostemma brevifilis, Moringa oleifera, Plinia cauliflora and Simarouba versicolor.

From pollen grain samples collected in a Cerrado area in the city of Campo Grande, Mato Grosso do Sul, images at different optical scales were captured using the Carls Zeiss model axis-scope A1 microscope. The amount of pollen grain images captured according to the optical scale is shown in Table II. 
TABLE II

THE NUMBER OF RAW IMAGES OF POLLEN GRAINS CAPTURED IN THE LABORATORY. THE IMAGES WERE SEPARATED BY SPECIES AND ALSO ACCORDING TO THEIR CORRESPONDING OPTICAL SCALE.

\begin{tabular}{llccccc}
\hline & & \multicolumn{5}{c}{ Quantity by scale } \\
\hline & \multicolumn{1}{c}{ Specie } & $5 \mathrm{x}$ & $10 \mathrm{x}$ & $20 \mathrm{x}$ & $40 \mathrm{x}$ & Total \\
\hline 1 & Azadirachta indica & 9 & 10 & 10 & 10 & 39 \\
2 & Banisteria argyrophylla & 10 & 10 & 10 & 14 & 44 \\
3 & Bauhinia & 12 & 10 & 10 & 9 & 41 \\
4 & Bixa orellana & 11 & 10 & 13 & 9 & 43 \\
5 & Camptostema ellipticum & 10 & 10 & 10 & 10 & 40 \\
6 & Casearia aculeata & 11 & 10 & 10 & 10 & 41 \\
7 & Cocos nucifera & 10 & 10 & 10 & 10 & 40 \\
8 & Euphorbia pulcherrima & 11 & 11 & 10 & 10 & 42 \\
9 & Handroanthus heptaphyllus & 10 & 12 & 9 & 10 & 41 \\
10 & Hidrocleys nymphoides & 10 & 10 & 11 & 10 & 41 \\
11 & Inga vera & 10 & 11 & 10 & 12 & 43 \\
12 & Leucaena leucocephala & 10 & 10 & 11 & 10 & 41 \\
13 & Matabba guianersis & 11 & 10 & 13 & 10 & 44 \\
14 & Mitostemma brevifilis & 32 & 30 & 32 & 17 & 111 \\
15 & Moringa oleifera & 10 & 10 & 10 & 10 & 40 \\
16 & Plinia cauliffora & 11 & 11 & 10 & 11 & 43 \\
17 & Simarouba versicolor & 10 & 9 & 10 & 11 & 40 \\
& TOTAL & 220 & 214 & 218 & 200 & 903 \\
\hline
\end{tabular}

As the purpose of this work is the discovery of the best optical scale for pollen grain imaging, the dataset was organized to divide the images according to their respective scale. Therefore, this image dataset is the pioneer to contain images of pollen grains at different visual scales in Brazil and is called Polen40k.

\section{B. Data Augmentation}

The Polen40k dataset has derived from 903 raw images. After preprocessing and data augmentation methods, it resulted in a total of 38.880 images. These images are divided into 17 various pollen species into different optical scales, being $5 \mathrm{x}$, 10x, 20x, and 40x, respectively.

After capturing images in the laboratory, the raw images were preprocessed generating a new bank containing 1440 images. In this process (step A of Figure 2) the pollen grains were segmented [15] from the original images and their names were annotated, afterward, 20 of these cropped images were randomly selected for each optical scale.

From the segmented 1440-image database, transformations were performed to increase data, which is necessary because deep learning techniques have better results according to the total number of images. The schematic shown in Figure 2 clarifies the sequence of data augmentation steps made here.

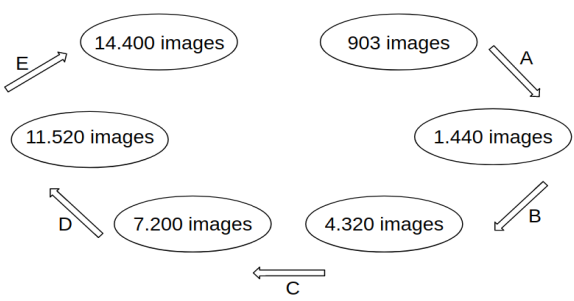

Fig. 2. The Polen40k image dataset has 903 raw images and from them, different image processing was performed in sequence $\mathrm{A} \rightarrow \mathrm{E}$ : Grain crop and noise deletion, 3 rotations, 5 rotations, 8 rotations with vertical rotation and by finish 8 more rotations with horizontal rotation plus 135 degrees rotation with both turns. Thus, 37.440 different images of pollen grains were totaled.

In Table III, it is possible to verify what were data augmentation performed in steps B, C, D, and E. A total of 37.440 synthetic images was generated with these transformations. Therefore, in addition to the original 1440 images, a database of 38.880 images available to be used in machine vision experiments for the advancement of science in palynology was created.

TABLE III

THE DATA AUGMENTATION TRANSFORMATIONS PERFORMED IN EACH OF THE STEPS (B, C, D E E). LATER, IN THIS STEP, 135 DEGREE ROTATION WITH BOTH VERTICAL AND HORIZONTAL ROTATION WAS ADDED..

\begin{tabular}{llccl}
\hline \multicolumn{1}{c}{ Step } & \multicolumn{1}{c}{$\begin{array}{c}\text { Rotation } \\
\text { (degrees) }\end{array}$} & $\begin{array}{c}\text { Vertical } \\
\text { Flip }\end{array}$ & $\begin{array}{c}\text { Horizontal } \\
\text { Flip }\end{array}$ & Generated \\
\hline B & 15,30 and 45 & No & No & 4320 \\
C & $\begin{array}{l}60,75,90,105 \\
\text { and } 120\end{array}$ & No & No & 7200 \\
& $\begin{array}{l}15,30,45,60, \\
\text { D }\end{array}$ & Yes & No & 11520 \\
E & $15,90,105$ and 120 & & & \\
TOTAL & 90,105 and $120 * *$ & No & Yes & 14400 \\
\hline
\end{tabular}

From the palynological slides, a chemical process of pollen grains treatment is executed, through the methods of acetolysis and fixation with glycerine gelatine, where it is possible to fix them for later image capture. The quality of the samples in these slides depends on external and biological factors, so each slide can't have the same amount of grain per species [16].

\section{Human Classification}

For human classification, a 68 images dataset was used. For each of the 17 species, 4 images were chosen randomly, each image on a different scale. This amount is because visually pollen classification is an exhausting and monotonous task, which makes it improbable for a specialist to classify a larger amount voluntarily.

The used approach on this classification was conducted using an online environment (Google forms), posted on social networks, for example, Palynology groups, on Facebook. In Table IV it is possible to see the palynology groups where the specialists were invited. Other systems, i.e. Whatsapp, were used to invite more specialists.

TABLE IV

OUR CLASSIFICATION FORM DESTINED FOR HUMAN CLASSIFICATION WAS POSTED ON THE BIGGEST PALYNOLOGY GROUPS AT FACEBOOK. THE IDEA WAS TO FIND VOLUNTEERS FROM THIS AREA TO CARRY OUT THIS CLASSIFICATION STEP.

\begin{tabular}{lcc}
\hline Name & $\begin{array}{l}\text { No. } \\
\text { Members }\end{array}$ & Country \\
\hline Palinologia & 639 & BR \\
NEPAL & 230 & BR \\
Asociación Latinoamericana & 372 & ARG \\
de Paleobotánica y Palinología & 242 & USA \\
Palynology and Biostratigraphy & 242 &
\end{tabular}

Before-mentioned, the classification was made online, through two online Google forms. As the classification consists of 68 images, each form had 34 images, and they could be found at https://forms.gle/UFcxSApVtmQHHhmV8 and https://forms.gle/jtQmpMx86RcGues19.

It is worth mentioning that, this classification is due to the human eye, so this process is susceptible to several errors since 
the activity is monotonous and exhausting. For example, the process follows for experts in the field to view grain by grain from different points of view over a computer screen during hours and hours. These palynology experts use additional material, which is known as Rede de Catálogos Polínicos, Pollen Catalog Network. This material helps to find pollen information, for example, those shown in Table V.

TABLE V

THE POLYNICAL DESCRIPTION THAT IS PRESENTED OVER THE POLLEN CATALOG NETWORK MATERIAL, USED FOR EXPERTS TO DO THE CLASSIFICATION.

\begin{tabular}{lll}
\hline Exine ornamentation & Pore feature & Type of pollen aperture \\
Number of apertures & Pollen polarity & Pollen size \\
Pollen amb & Pollen shape & Colpo feature \\
Pollen dispersal unit & Pollen symmetry & Location \\
\hline
\end{tabular}

In addition to their regular use of this material, we provided train images as extra material. For each species, 4 images withdrawal from each zoom were randomly chosen, constituting a training dataset for those who wanted to memorize some visual information on their mind. This material could be found at https://forms.gle/EeDCxr7XWJLjwuA76.

Twenty experts initialized the process. The group was composed of various areas that could be applied in palynology. They were: biology, ecology, forestry engineering, and computer engineering undergraduate students. Also, agriculture masters and biology, ecology, geology, and palynology doctors participated. Unfortunately, from this group, just four experts had finished the classification.

\section{Machine Classification}

Two phases of experiments were performed, the first consisting of using five shallow learning methods [17] and the second five deep learning methods [18], as shown in Table VI.

TABLE VI

METHODS USED IN THE EXPERIMENTS.

\begin{tabular}{cc}
\hline Shallow Learning & Deep Learning \\
\hline IBk $(k=1)$ & Xception \\
IBk $(k=5)$ & VGG16 \\
SMO & VGG19 \\
j48 & ResNet50 \\
Random Forest & InceptionV3 \\
\hline
\end{tabular}

A total of 80 different configurations were performed, established in the following order: all algorithms were used to classify the pollen grains present in the 4 different scales, using the 1440 image dataset, to verify which method would have the best results. Subsequently, with the best method selected, 4320, 7200, 11520, and 14400 image datasets, evaluations were performed, both separated by scales, to verify visual zoom interference on digital images and to validate whether such interference has significant relevance.

1) Shallow Learning: In Phase 1, the machine vision steps [19], [20] were performed before the shallow learning classification process, and the extraction of image attributes included the following extractors: color statistics, gradient histogram,
Hu moments, image moments, local binary patterns and Gabor filtering [11], [21].

The Polen40k was hold-out into $60 \%$ of data for training and the remaining $40 \%$ of the data were used for the testing process [22]. No copies of the same image appear in both training and test sets simultaneously, since it would lead to an incorrect performance evaluation of the demonstrated methods. Nevertheless, Cross-validation being a preferred method rather than Hold-out was not used since it requires more computational power and time, moreover, this work does propose an initial knowledge about human versus machine classification. In light of this, the 5 shallow learning algorithms (Table VI) were used.

The following metrics were extracted: True Positive Rate (ie the pollen grains the classifier correctly named), False Positive Rate (ie the pollen grains the classifier said were not and indeed were not), Precision (ie, performs a calculation using TP and FP), Recall (ie, performs a calculation using TP and FN, which are the grains he misclassified), F-Measure (ie, combines precision and recall to bring a unique number that indicates the overall quality of the model) and finally, the Area under ROC curve (ie a metric value calculated from a curve on a graphic that has two axes, the TP and the FP. The results obtained are shown in Table IX.

The metrics explained above have the following formulas:

- Precision $=\frac{T P}{(T P+F P)}$

- Recall $=\frac{T P}{(T P+F N)}$

- $F=2 * \frac{(\text { Precision } * \text { Recall })}{(\text { Precision }+ \text { Recall })}$

2) Deep Learning: In Phase 2, the deep convolutional neural network models were implemented using the Keras application, based on TensorFlow [18]. These models had already been published and are known for having the best results at ImageNet [23].

The training was done starting from pre-trained models on Imagenet, even though the number of images was 903. It is important to notice that each model has different layers of topology, however, the activation functions used were the same. ReLu activation function was used on the fully connected layer, and the softmax activation function was used to execute the training predictions.

As following, the informations belonging to each model are shown:

TABLE VII

LAYERS AND PARAMS OF EACH IMPLEMENTED MODEL.

\begin{tabular}{cccc}
\hline Model & Layers & Params & Optimizer \\
\hline Xception & 132 & $20,861,480$ & SGD \\
VGG16 & 19 & $14,714,688$ & SGD \\
VGG19 & 22 & $20,024,384$ & SGD \\
ResNet50 & 175 & $23,587,712$ & SGD \\
InceptionV3 & 311 & $21,802,784$ & SGD \\
\hline
\end{tabular}

The pre-processing of networks input was done by image data generator -a Keras function to read data- to rescale the images to $0-1$ instead of their pixel values being $0-255$. On the network's output custom layers were added. A flatten method following by a fully connected layer with a dropout. 
All models used the same initial parameter values: 0.001 learning rate, 0.9 momentum, 16 as batch size, 200 epochs, did not use the transfer learning technique and neither fine-tuning adjustments and the percentage of data distribution continued to be $60 \%$ for the training and $40 \%$ for the classification test [24].

It is important to remember that in the shallow learning algorithms the displayed metric used is the true positive rate and for the deep learning algorithms is the accuracy rate, both quantify the system's effectiveness in correctly classifying pollen grains. It is also worth regarding that both were run on different computers, shallow learning on an i7-7700hq processor and Nvidia 1050ti graphics card, and the deep learning on an i7-7700 processor and Nvidia titan XP GPU, but this comparison does not conflict with the results shown, in time execution and memory consumption only.

\section{Results And Discussion}

Initially, a comparison with the 68 images dataset used for the human classification being also used as a test dataset for the machine classification was evaluated. In the human eye classification, all the participants had low results in the $5 \mathrm{x}$ scale and contrast, high on the 40x scale. Thus, the average result of the $5 \mathrm{x}$ scale was $25.00 \%$, the 10x scale was $35.29 \%$, in $20 \mathrm{x}$ it was $44.18 \%$ and finally in $40 \mathrm{x}$ the best result, being $45.59 \%$. The human results can be seen in Table VIII.

TABLE VIII

THE CORRECT PERCENTAGE RATE OF EXPERT PARTICIPANTS (PS) FOR VISUAL CLASSIFICATION ON EACH OF THE FOUR OPTICAL SCALES. EXECUTION DONE THROUGH A QUESTIONNAIRE WITH 68 IMAGES.

\begin{tabular}{ccccc}
\hline & Ps 1 & Ps 2 & Ps 3 & Ps 4 \\
\hline $\mathbf{5 x}$ & 29.41 & 29.41 & 17.65 & 23.53 \\
$\mathbf{1 0 x}$ & 47.59 & 47.59 & 23.53 & 23.53 \\
$\mathbf{2 0 x}$ & 58.82 & 58.82 & 29.41 & 29.41 \\
$\mathbf{4 0 x}$ & 47.59 & 52.41 & 35.29 & 47.59 \\
\hline
\end{tabular}

Meanwhile, the 1440 images dataset was used to check the machine classifications zoom pattern. The results of the shallow learning method show that the best pollen grain imaging scale is over again $5 \mathrm{x}$, and the algorithm that had the best results in this approach was the Random Forest. Deep learning was also used and thus validated the best pollen grain capture scale is indeed the $5 \mathrm{x}$, being ResNet50 the best classifier. These results are presented in Table IX.

As a result, the smaller the scale the better the result when the classification is done by the machine could be explained by a large amount of unnecessary information. When the optical scale is low the amount of noisy information makes no difference, that is, the opposite from high scales, when there are too many details to deal with that it turns into a complex learning process.

In consequence of Random Forest and ResNet50 obtained the best scores rates, subsequently, they were chosen to perform experiments with the largest image datasets. Using these algorithms, 40 configurations were conducted, to verify if the smallest scale still keeps the best classification results
TABLE IX

THE CLASSIFICATION RESULTS OF THE MACHINE LEARNING ALGORITHMS USED AT EACH OF THE FOUR OPTICAL SCALES. EXECUTION MADE IN THE DATASET OF 1440 IMAGES.

\begin{tabular}{|c|c|c|c|c|c|}
\hline & $\begin{array}{c}\text { ibk } \\
(k=1)\end{array}$ & $\begin{array}{c}\text { ibk } \\
(k=5)\end{array}$ & SMO & j48 & $\begin{array}{c}\text { Random } \\
\text { Forest }\end{array}$ \\
\hline $5 x$ & 70.33 & 64.83 & 78.81 & 61.94 & 79.39 \\
\hline $10 x$ & 61.89 & 58.11 & 68.64 & 54.47 & 71.25 \\
\hline $20 x$ & 55.72 & 47.06 & 62.14 & 53.08 & 71.17 \\
\hline \multirow[t]{2}{*}{$40 x$} & 40.28 & 36.11 & 48.92 & 35.39 & 54.50 \\
\hline & Xception & $\begin{array}{c}\text { Inception } \\
\text { V3 }\end{array}$ & $\begin{array}{c}\text { VGG } \\
16\end{array}$ & $\begin{array}{c}\text { VGG } \\
19\end{array}$ & $\begin{array}{c}\text { ResNet } \\
50\end{array}$ \\
\hline $5 x$ & 90.28 & 97.92 & 95.82 & 95.83 & 96.83 \\
\hline $10 x$ & 82.94 & 97.92 & 95.38 & 95.14 & 96.53 \\
\hline $20 x$ & 82.64 & 96.53 & 95.38 & 95.14 & 95.14 \\
\hline $40 x$ & 72.92 & 84.72 & 86.06 & 82.42 & 88.89 \\
\hline
\end{tabular}

and if the data increase has significant improvement in the score. The results are represented in Table X.

TABLE $X$

THE CLASSIFICATION RATES OF THE RANDOM FOREST AND RESNET50 ALGORITHMS ON EACH OF THE FOUR OPTICAL SCALES RESPECTIVE FROM EACH OF THE DATA AUGMENTATION DATASETS.

\begin{tabular}{|c|c|c|c|c|c|}
\hline & \multicolumn{5}{|c|}{ Random Forest } \\
\hline & 1440 & 4320 & 7200 & 11520 & 14400 \\
\hline $5 x$ & 79.39 & 98.70 & 82.89 & 92.33 & 95.78 \\
\hline $10 x$ & 1.2 & 99.17 & & & 96.67 \\
\hline $20 x$ & 1.17 & 19. & 83 & 94 & 97.14 \\
\hline \multirow[t]{3}{*}{$40 x$} & 1.50 & 96.67 & 71.72 & 88.51 & 93.78 \\
\hline & \multicolumn{5}{|c|}{ ResNet50 } \\
\hline & 1440 & 4320 & 7200 & 11520 & 14400 \\
\hline $5 x$ & 96.83 & 98.29 & 99 & 99.83 & 99.72 \\
\hline $10 x$ & 6.53 & 8.29 & & 99.83 & 99.99 \\
\hline $20 x$ & 5.14 & 8.11 & 99. & 99.74 & 99.99 \\
\hline $40 x$ & 88.89 & 94.08 & 99.86 & 99.99 & 99.99 \\
\hline
\end{tabular}

In addition, it has been observed that convolutional neural networks, current state-of-the-art image classification methods, actually defeat traditional algorithms, in Table $\mathrm{X}$ the more images there are, the better machine learning gets, but CNN's stand out. In the first technique, the Random Forest algorithm stood out, achieving $69.08 \%$ of overall performance. In the second technique, the ResNet50 algorithm was the best, obtaining $97.80 \%$ of overall performance.

Figure 3 (a) shows the graphic of ResNet50's accuracy result in the 1440 image dataset is shown. Accuracy results were $97.92 \%, 96.53 \%, 95.14 \%$ and $88.89 \%$ respectively at the 5, 10, 20 and 40x scales. Next, the loss rate can be seen in part (b), being $0.14 \%, 0.14 \%, 0.16 \%$ and $0.36 \%$.

Further, the accuracy and error results from the 14400 image dataset can be seen in Figure 4. The maximum accuracy values were: $99.72 \%$ with an error of $0.0077 \%$ on the $5 \mathrm{x}$ scale, and $99.99 \%$ and an error values of $0.0005 \%$ for the other scales, respectively.

It can also be proved that manually increasing data for shallow machine learning techniques is of utmost importance as it significantly improved the evaluation rate by $21 \%$ on the $5 \mathrm{x}$ scale, $28 \%$ on the $10 \mathrm{x}$ and $20 \mathrm{x}$ scales, and $43 \%$ on the 40x scale, ie $30 \%$ improvement in overall score (improvement 


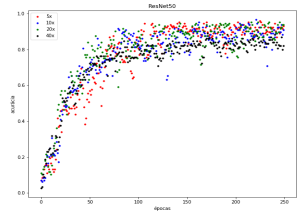

(a)

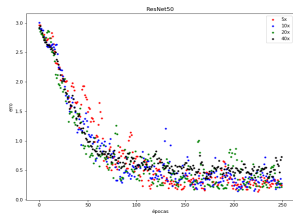

(b)
Fig. 3. Accuracy (a) and loss (b) of the ResNet50 convolutional neural network performed on the 1440 images dataset.

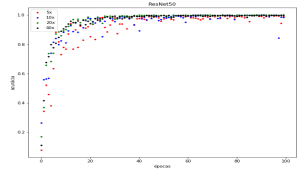

(a)

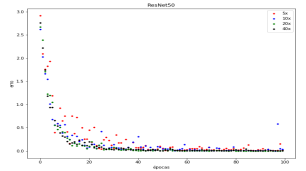

(b)
Fig. 4. Accuracy (a) and loss (b) of the ResNet50 convolutional neural network performed on the 14400 images dataset.

rates from step B of Figure 2) and that after a certain amount of images this rate maintains, as seen in Table $\mathrm{X}$, indicating that for larger amounts of images the best technique to use is deep learning.

\section{CONCLUSION}

This work proposes a new approach for microscope pollen grain imaging. A standard for capture has been established to avoid overwork on other optical scales that are not of significant relevance. First, 40 different configurations were executed with shallow learning algorithms and were identified as a better recognition pattern on the $5 x$ scale. Second, 40 more configurations with deep learning algorithms were performed to verify the same pattern, and the obtained results validate this new point of view. Therefore, it was verified that for machine techniques of automatic pollen grain classification, the best-established scale was 5x. Already in the experiment with humans, were tested if the human mind has the same outcomes as the machine, and it was validated that the human eye classifies the grains in the opposite way to the algorithms, that is, the largest scale has the best results and so. Similarly, the smallest scale gives the worst results, unlike the machine. Furthermore, were adopted two different machine learning techniques for grain classification, shallow learning, and deep learning, and the results found that the use of CNN's outperforms traditional algorithms. As future work, we hope to do experiments with a larger number of participants and images.

\section{ACKNOWLEDGMENT}

This work has received financial support from the Dom Bosco Catholic University, UCDB and the Foundation for the Support and Development of Education, Science and Technology from the State of Mato Grosso do Sul, FUNDECT. Some of the authors have been awarded Scholarships from the Brazilian National Counsel of Technological and Scientific
Development, $\mathrm{CNPq}$, and the Coordination for the Improvement of Higher Education Personnel, CAPES. We gratefully acknowledge the support of NVIDIA Corporation with the donation of the Titan Xp GPU used for this research.

\section{REFERENCES}

[1] O. V. D., O. W., P. L., P. M. L., M. M., and P. M., "Harmonized methods of melissopalynology," Apidologie, vol. 35, no. Suppl. 1, pp. S18-S25, 2004.

[2] S. A.P, P. M. C., P. J. C., and S. T. D. M., "A utilização da ciência forense e da investigação criminal como estratégia didática na compreensão de conceitos científicos," Educación Química, vol. 24, no. 1, pp. 49 - 56, 2013. [Online]. Available: http://www.sciencedirect.com/science/article/pii/S0187893X13731951

[3] B. T. NUNES, D. J.; CAMPOLINA, "A importância da botânica forense na resolução de crimes," 64 Congresso Nacional de Botânica, 2013.

[4] J. S. T. and W. J. W., Modern analogs in Quaternary paleoecology: here today, gone yesterday, gone tomorrow?, 2004, vol. 32.

[5] G. Allen, R. M. Hodgson, S. Marsland, G. Arnold, R. Flemmer, and J. Flenley, "Automatic Recognition of Light-Microscope Pollen Images," 2019.

[6] A. B. GONCALVES, J. S. SOUZA, G. G. d. SIlVA, M. P. CEREDA, A. POTT, M. H. NAKA, and H. PISTORI, "Feature extraction and machine learning for the classification of brazilian savannah pollen grains," Plos One, 2016.

[7] A. B. Gonçalves, J. S. Souza, G. G. d. Silva, M. P. Cereda, A. Pott, M. H. Naka, and H. Pistori, "Feature extraction and machine learning for the classification of brazilian savannah pollen grains," PLOS ONE, vol. 11, pp. 1-20, 06 2016. [Online]. Available: https://doi.org/10.1371/journal.pone.0157044

[8] C. M. H. C. M. P. H. QUINTA L. N. B, AMORIM W. P., "Floresta de caminhos Ótimos na classificacação de pólen,” WVC 2012 - Workshop de Visão Computacional, 2012

[9] G. A. B. C. M. P. H. QUINTA L. N. B., ANDRADE W. T., "Segmentacão baseada em textura e watershed aplicada a imagens de pólen,' SIBGRAPI 2012 - Workshop of Undergraduate Work - WUW-, 2012.

[10] M. Rodriguez-Damian, E. Cernadas, A. Formella, M. FernándezDelgado, and P. De Sa-Otero, "Automatic detection and classification of grains of pollen based on shape and texture," IEEE Transactions on Systems, Man, and Cybernetics, Part C (Applications and Reviews), vol. 36, no. 4, pp. 531-542, 2006.

[11] C. N. M. C. M. P. H. GONÇALVES, A. B.; RODRIGUES, "Identificação computadorizada de tipos polínicos através de "bag of words"," WVC 2016 - Workshop de Visão Computacional, 2016.

[12] G. Lozano-Vega, Y. Benezeth, F. Marzani, and F. Boochs, "Classification of pollen apertures using bag of words," in International Conference on Image Analysis and Processing. Springer, 2013, pp. 712-721.

[13] G. A. B. P. H. B. M. QUINTA L. N. B., SILVA D. S., "Application of wavelet transform in the classification of pollen grains," Academic Journals, African Journal of Agricultural Research, 2014.

[14] V. Sevillano and J. L. Aznarte, "Improving classification of pollen grain images of the polen23e dataset through three different applications of deep learning convolutional neural networks," PLOS ONE, vol. 13, no. 9, pp. 1-18, 09 2018. [Online]. Available: https://doi.org/10.1371/journal.pone.0201807

[15] F. A. S. R, "Redes neurais convolucionais profundas na detecção de plantas daninhas em lavoura de soja," Tese (Doutorado), 2017.

[16] M. A. M. and CARVALHO. (2015) Palinologia forense. [Online]. Available: http : //apcforenses.org/?page f $_{i}=502$

[17] B. J. MONARD M.C., Conceitos de aprendizado de máquina, 2003.

[18] A. N. G., Machine Learning Yearning: Technical Strategy for AI Engineers, In the Era of Deep Learning. deeplearning.ai, 2018.

[19] Q. L.N.B, "Visão computacional aplicada na classificação de grãos de pólen," Dissertação (mestrado em Biotecnologia) - Universidade Católica Dom Bosco - UCDB, 2013.

[20] M. MARENGONI and D. STRINGHINI, "Tutorial: Introdução à visão computacional usando opencv," 062018.

[21] P. H. (2017) PecuÁria de precisÃo como fator de desenvolvimento local da regiÃo do alto taquari. [Online]. Available: http://www.gpec.ucdb.br/pistori/orientacoes/planos/gilberto2016.pdf

[22] G. M. TOMMASELLI A.M.G., HASEGAWA J. K., "Modernas tecnologias de aquisição de imagens em fotogrametria," Boletim de Ciências, 2000 . 
[23] J. Deng, W. Dong, R. Socher, L.-J. Li, K. Li, and L. Fei-Fei, "Imagenet: A large-scale hierarchical image database," pp. 248-255, 2009.

[24] A. V. C. N. VARGAS, A. C. G.; PAES, "Um estudo sobre redes neurais convolucionais e sua aplicacão em deteccão de pedestres," SIBGRAPI Conference on Graphics, Patterns and Images, 2016. 